\title{
A POLÍTICA PÚBLICA DOS JARDINS DE RECREIO COMO ESPAÇO CIVILIZADOR NO CONTEXTO URBANO DE PORTO ALEGRE (1920-1950)
}

\author{
Fabiana Gazzotti Mayboroda ${ }^{1}$ \\ Luciane Sgarbi Santos Grazziotin ${ }^{2}$
}

\section{RESUMO}

Este estudo diz respeito aos Jardins de Recreio, uma política pública instituída na cidade de Porto Alegre/RS a partir dos anos 1920. Objetiva compreender suas condições de implementação e suas interfaces com o processo educacional. Fundamenta-se na análise documental histórica, que possibilita compreender as condições de instauração e funcionamento dos Jardins de Recreio, sua característica educadora e sua relação com a urbanidade. Percebe-se que os Jardins de Recreio se constituíram em espaços de sociabilidade e lazer dos porto-alegrenses, para além de uma intenção pedagógica fomentada pelas modificações urbanas, pelo discurso higienista e civilizatório deflagrado pela modernidade.

Palavras-chave: processo civilizador, urbanização, jardins de recreio, higienismo, história da educação.

${ }^{1}$ Universidade Federal do Rio Grande do Sul (UFRGS), Porto Alegre/RS, Brasil.

${ }^{2}$ Universidade do Vale do Rio dos Sinos (Unisinos), São Leopoldo/RS, Brasil. 


\section{LA POLÍTICA PÚBLICA DE LOS JARDINES DE RECREO COMO ESPACIO CIVILIZADOR EN EL CONTEXTO URBANO DE PORTO ALEGRE (1920-1950)}

\section{RESUMEN}

Este estudio se refiere a una política pública instituida en la ciudad de Porto Alegre/RS a partir de los años 1920, denominada Jardines de Recreo. Tiene como objetivo comprender sus condiciones de implementación y sus interfaces con el proceso educacional. Está fundamentada en el análisis documental histórico, que posibilita comprender las condiciones de instauración y funcionamiento de los Jardines de Recreo, su característica educadora y su relación con la urbanidad. Se percibe que los Jardines de Recreo se constituyeron en espacios de sociabilidad y placer de los porto-alegrenses, más allá de una intención pedagógica fomentada por las modificaciones urbanas, por el discurso higienista y civilizatorio propagado por la modernidad.

Palabras clave: proceso civilizador, urbanización, jardines de recreo, higienismo, historia de la educación.

\section{THE PUBLIC POLICY OF RECREATIONAL GARDENS AS A CIVILIZATORY SPACE WITHIN THE URBAN CONTEXT OF PORTO ALEGRE (1920-1950)}

\section{ABSTRACT}

This study is about Recreational Gardens, a public policy instituted in the city of Porto Alegre/RS from the 1920s. It aims at understanding its conditions of implementation and its interfaces with educational processes at the time. It is based on a historical documentary analysis, which enables the understanding of the conditions of instauration and functioning of the Recreational Gardens, its pedagogical characteristic and its relation with urbanity. It is possible to observe that the Recreational Gardens represented spaces of sociability and leisure for the porto-alegrenses, beyond a pedagogical intention fostered by the urban modifications, the hygienist and the civilizatory discourse flared by modernity.

Keywords: civilizatory process, urbanization, recreational gardens, hygienism, history of education.

\section{LA POLITIQUE PUBLIQUE DES JARDINS RÉCRÉATIFS COMME ESPACE CIVILISANT DANS LE CONTEXTE URBAIN DE PORTO ALEGRE (1920-1950)}

\section{RÉSUMÉ}

Cette étude concerne une politique publique instaurée dans la ville de Porto Alegre/RS à partir de la décennie des années 1920, appelée Jardins de Récréation. Elle a comme objectif celui de saisir les conditions d'implémentation de cette Politique et ses interfaces avec le processus éducationnel. La recherche est basée sur l'analyse documentaire historique, avec laquelle il a été 
possible de comprendre les conditions d'instauration et de fonctionnement des Jardins de Récréation, leur caractéristique éducatrice et leur relation avec l'urbanité. On observe que les Jardins de Récréation, instaurés dans les places et dans les parcs publics de la ville ont constitué les espaces de sociabilité et de loisir des habitants de Porto Alegre, au-delà d'une intention pédagogique provoquée par les modifications urbaines, par le discours hygiéniste et de la civilisation déclenché par la modernité.

Mots-clés: processus de la civilisation, urbanisation, jardins de récréation, hygiénisme, histoire de l'éducation. 


\section{INTRODUÇÃO}

Na cidade de Porto Alegre, durante a segunda metade do século XIX, ocorreram grandes transformações em relação à infraestrutura citadina. Nesse processo, as alterações estruturais não são somente geográficas; há também alterações urbanas realizadas pela apropriação e pela interferência de grupos sociais organizados. A intervenção desses grupos está relacionada à crescente complexidade das organizações sociais decorrentes, em certo sentido, da abolição da escravidão, da chegada de muitos imigrantes, das mudanças das pessoas do campo para a cidade, do processo de industrialização e do alto índice de nascimentos. Nesse sentido, para Pesavento (1999), a diversificação econômicosocial da população e as transformações arquitetônicas fomentaram a proliferação de becos e cortiços, revelando a vida em cidade.

Tais transformações urbanísticas e o crescimento demográfico provocaram uma sensação de desconforto, que reivindica uma reordenação do espaço urbano, processo acompanhado por uma campanha de saneamento da cidade. Nesse contexto, há um projeto de ampliação da intervenção da medicina e da assistência social, o que amplia, em alguma medida, o conhecimento médico no domínio social. Instituem-se, assim, práticas de controle de doenças e de saneamento, que intervêm sobre a organização do modo de vida das pessoas. Tais práticas estabeleceram uma teia de intervenção sanitarista, de assistência clínica, terapêutica e educacional, assegurando a circulação de discursos médicos pelo tecido social. Segundo Popkewitz (2010), o homem civilizado trabalharia com o governo, por meio de reformas, para eliminar todos os males, fossem eles físicos ou morais. Portanto, conforme Stephanou (2006, p. 36), “os médicos transitaram dos consultórios e hospitais às tribunas, [...] das escolas às faculdades, das instituições à intimidade dos lares”.

Esse enredo urbano, permeado pelo discurso da modernidade, produz, ao longo do primeiro quartel do século XX, novo imaginário social para a cidade de Porto Alegre. Outros sujeitos passaram a ser constituídos “[...] na articulação 
complexa de discursos e práticas, que podem ser pedagógicos, médicos, terapêuticos, entre outros, historicamente engendrados, que instauram modos de conhecimento de si" (STEPHANOU, 1998, p. 97).

É nesse contexto que, no ano de 1926, foi implementada uma política pública pioneira no Brasil, idealizada pelo Professor Frederico Gaelzer, que objetivava a ampliação do acesso as práticas de esporte e lazer relacionadas aos processos educativos, denominada de "Jardins de Recreio".

O estudo desenvolvido tem o objetivo de compreender as condições de implementação dessa política pública e as suas interfaces no processo educacional; para tanto entende as "[...] relações econômicas e sociais como campos da prática cultural e de produção cultural” (HUNT, 1992, p. 9). Foi com essa perspectiva que se deu a análise documental da investigação.

\section{A PESQUISA E SEUS MEANDROS}

Um processo importante na construção de um trabalho historiográfico é a garimpagem dos documentos, incluindo sua seleção e análise. A expressão garimpagem é utilizada por Farge (2009) para sinalizar a importância de determinadas palavras encontradas nos documentos que permitem ao historiador identificar e compreender o momento e articulá-lo ao foco de seu estudo. Os documentos acessados, sobre os quais o corpus empírico dessa investigação foi construído, pertencem ao acervo documental do Centro de Memória do Esporte da Universidade Federal do Rio Grande do Sul (Ceme)3. O Ceme "[...] foi implementado em janeiro de 1997 com o objetivo de reconstruir, preservar e divulgar a memória do esporte, da Educação Física, do lazer e da dança no Brasil” (GOELLNER; MACEDO; SILVA, 2013, p. 2). O acervo, digitalizado de uma coleção denominada Lazer e Recreação Pública, constituiu, portanto, a centralidade de fontes deste estudo.

3 Para maiores informações, consultar o site: http://www.ufrgs.br/ceme/acervo.php. 
Partindo-se de documentos escritos, sobretudo diários, leis, decretos e atas oficiais, assim como plantas da arquitetura urbana, desenhos e croquis de praças e bairros da cidade, foi possível seguir os vestígios dos Jardins de Recreio em suas dimensões educativas e de sociabilidade urbanas.

O mesmo acervo é constituído também de entrevistas; são memórias de sujeitos historicamente ligados à faculdade de Educação Física da UFRGS e/ou ao Serviço de Lazer e Recreação Pública de Porto Alegre. Para este estudo, foram selecionadas as entrevistas de Henrique Felippe Bonnet Licht e Lilian Gaelzer Wertheimer, em virtude de sua relação com os Jardins de Recreio, o Serviço de Recreação Pública e, sobretudo, com Frederico Guilherme Gaelzer. Os nomes dos entrevistados são explicitados por ser essa pesquisa de cunho historiográfico; esses sujeitos, acredita-se, fazem parte da história de Porto Alegre e, portanto, precisam ser visibilizados.

Segundo Halbwachs (1990), nossas lembranças são coletivas, pois o indivíduo é inserido e constituído por grupos. Nesse sentido, os grupos apresentam-se de forma relevante para a construção da memória. Para o autor,

Se nossa impressão pode apoiar-se não somente sobre nossa lembrança, mas também sobre a de outros, nossa confiança na exatidão de nossa evocação será maior, como se uma mesma experiência fosse começada, não somente pela mesma pessoa, mas por várias (1990, p. 25).

As memórias de Henrique Felippe Bonnet Licht e Lilian Gaelzer Wertheimer, perenizadas no acervo de memória oral do Ceme ${ }^{4}$, estão intimamente ligadas à memória coletiva de uma cidade e se transformaram de acordo com o lugar social que esses indivíduos ocuparam, nos diferentes grupos dos quais fizeram parte (HALBWACHS, 1990). Esse conjunto documental

\footnotetext{
4 A divulgação das entrevistas na íntegra se origina do projeto de pesquisa "Garimpando Memórias”, desenvolvido pelo Ceme desde 2002 (GOELLNER; MACEDO; SILVA, 2013, p. 3). Mais informações estão disponíveis em: http://www.esef.ufrgs.br/ceme/projetos/garimpando/ index.htm.
} 
permitiu a historiografia dos Jardins de Recreio como uma política pública que articula aspectos relativos à urbanidade, à civilidade e à educação.

Foi por meio do planejamento urbano, da concretização das obras de infraestrutura e da preocupação, por parte da Intendência, em melhorar a condição de vida das pessoas que as primeiras praças da cidade foram, paulatinamente, construídas e ocupadas pelos porto-alegrenses, instituindo formas singulares de sociabilidade e de lazer.

Para Castells (2010), quando a sociedade passa por transformações, outras formas e processos espaciais surgem. Neste sentido, a carência de lugares públicos para o acesso da população, bem como o investimento em educação, saúde, higiene, esporte e recreação, sob o foco da prevenção, tornaram as praças um local viável para o desenvolvimento de ações e intervenções.

A cidade de Porto Alegre foi entendida como um cenário privilegiado para viabilizar um conjunto de práticas voltadas para a execução de objetivos higienistas; nesse processo, a educação foi entendida como espaço para a difusão de meios de prevenção e preservação da saúde. É importante salientar, no entanto, que tais objetivos não foram circunscritos apenas ao âmbito educacional.

Desse modo, em um contexto de transformações sociais, impregnados do discurso de modernização, houve, na capital gaúcha, um conjunto de leis e decretos que foram utilizados como instrumento de higienização da cidade e, consequentemente, da população. Parte-se do pressuposto de que a nova ordem social seria engendrada por outra ordem urbana. Assim, conforme Topalov (1996), a "questão urbana" emerge como uma transformação da "questão social". E é nessa transformação que, segundo Pesavento (1999), a cidade foi redesenhada, a exemplo da Europa no século XIX, por meio de uma intervenção urbana do tipo haussmaniana5, alargando ruas e avenidas.

\footnotetext{
5 Georges-Eugène Haussmann ficou conhecido como Barão Haussmann, o "artista demolidor". Foi prefeito do antigo departamento do Sena, que incluía os atuais departamentos de Paris, Hauts-de-Seine, Seine-Saint-Denis e Val-de-Marne, entre 1853 e 1870. Durante aquele período, foi responsável pela reforma urbana de Paris, determinada por Napoleão III, e tornou-se muito conhecido na história do urbanismo e das cidades. Mais informações estão disponíveis em:
} 


\section{LEGISLAÇÃO E URBANIZAÇÃO EM PORTO ALEGRE}

Ao longo da história, os estudos urbanísticos da cidade de Porto Alegre foram realizados por engenheiros dentro de uma Secretaria de Obras - na maioria dos casos, pautados por práticas importadas de outros países. Portanto, no urbanismo de Porto Alegre, há muito dos princípios, sobretudo, europeus. Entretanto, houve modificações em seu processo para mais bem adequar tais pressupostos às necessidades locais. As propostas de caráter específico estão relacionadas com a modernização, a higienização e o nacionalismo (PECHMAN, 1996).

A intervenção do Estado foi intensa na década de 1920, momento em que foram implementadas políticas públicas específicas, relacionadas ao contexto da Urbanização. Nesse sentido, destacam-se as seguintes mudanças legislativas: Decreto n. 8, de $1^{\circ}$ de julho de 1925, que regulamenta o emprego de condutores subterrâneos na zona central da cidade; Lei n. 89, de 15 de abril de 1926, que autoriza a abertura de crédito especial para aquisição de maquinários para o serviço de conservação de ruas e estradas; Decreto n. 52, de 06 de maio de 1926, que cria uma comissão para obras novas; Decreto n. 57, de 16 de junho de 1926, que estabelece o prazo de seis meses para a substituição das paredes de madeira, por alvenaria, das residências; Decreto n. 59, de 2 de julho de 1926, que providencia o serviço de vistorias em prédios de habitação coletiva; Decreto $\mathrm{n}$. 153, de 10 de agosto de 1928, que cria a Diretoria Geral de Saneamento; Decreto n. 163, de 21 de dezembro de 1928, que promove o Serviço de Instalações de Água e Esgoto; e Lei n. 247, de 28 de dezembro de 1928, que autoriza a criação de uma Brigada da Saúde.

Com esse conjunto de decretos e leis, o Estado assume um lugar de destaque na elaboração da política sanitária municipal, produzindo um discurso sobre a "questão urbana", providenciando a elaboração de estratégias de

https://www.britannica.com/biography/Georges-Eugene-Baron-Haussmann. Acesso em: 20 set. 2017. 
intervenção que continuam, em maior ou menor medida, durante as décadas de 1930, 1940 e 1950. Tais intervenções evidenciam-se, sobretudo, em 1950, com a promulgação da Lei n. 383, de 03 de março de 1950, que estabelece o Código de Posturas Municipais. A Lei, enquanto marco regulatório da vida citadina, articula disposições legais e designa regras de convivência em sociedade. As normas regulatórias tinham uma grande variedade; as preocupações contidas no documento vão desde os cuidados com as ruas e as praças, até o modo como deveria ser a fiscalização dos estabelecimentos. As infrações ao Código de Posturas eram punidas por meio do pagamento de taxas.

O Código de Posturas possuía um caráter modernizador e fomentava as modificações no espaço urbano. Porém, tais transformações não aconteciam sem tensões ou conflitos entre a população e o Estado (CHALHOUB, 1996). Ao analisar os processos de transformação social relacionados à civilidade urbana, Elias afirma que as normas de convívio social empreenderam um esforço para criar códigos; "neste caso, também, a transformação da existência social como um todo é a condição básica para civilizar-se a conduta" (ELIAS, 1993, p. 212). Acredita-se que o marco regulatório do Código não pode ser analisado de maneira isolada, pois se apresenta como uma característica de mudança, uma concretização de processos sociais. Assim sendo, "é essa ordem de impulsos e anelos humanos entrelaçados, essa ordem social, que determina o curso da mudança histórica, e que subjaz ao processo civilizador” (ELIAS, 1993, p. 194).

É no contexto dessa trama social que se justificou a importância da recreação pública e dos Jardins de Recreio, por meio da intenção de propiciar às crianças ocupações sãs, com atividades que beneficiassem a saúde, a cidadania e a moralidade. Nesse processo, autoridades de diferentes instâncias da administração pública se destacam; entre elas, está o professor Frederico Guilherme Gaelzer Netto. 


\section{FREDERICO GUILHERME GAELZER, OS JARDINS DE RECREIO E O DISCURSO MODERNO}

Filho de Ema Bender Gaelzer e Guilherme Gaelzer Netto, ambos de origem alemã, Frederico Guilherme Gaelzer nasceu em São Leopoldo, no Rio Grande do Sul, em 29 de julho de 1897; pertencia a uma família de destaque no cenário público gaúcho, com forte ligação com o Partido Republicano.

Em decorrência do prestígio familiar e de seu destaque no cenário político, sobretudo da Região do Vale dos Sinos, Guilherme Gaelzer viria a seguir o legado familiar e a ocupar também posição de destaque na política gaúcha.

O seu percurso indica experiências em âmbito internacional, relações externas e contatos com diferentes ideias desenvolvidas fora do Brasil; isso fica implícito no seu processo de formação e nas ideias que defendeu. Gaelzer cursou o ensino em nível médio na Alemanha, retornando para realizar a prova da Marinha, que era o desejo da família. Em torno de seus vinte anos, foi para os Estados Unidos, em princípio para estudar medicina; cursou, no entanto, Educação Física e Lazer na Universidade de IIlinois, em Chicago. Entre os anos de 1921 (ano de sua formatura) e 1922, o professor Frederico é designado pela Associação Cristã de Moços (ACM) para implantar uma sede no Uruguai, retorna ao Brasil e, em 1924, e inicia seus estudos sobre as praças da cidade.

No seu retorno, não consegue colocar em prática algumas ideias as quais vinha trabalhando ao longo da sua formação. Conforme o depoimento, bastante decepcionado, pensava em ir embora do Rio Grande do Sul.

Foi por meio de sua ligação de amizade com o Newton que o professor Frederico conseguiu ser apresentado para um deputado, Carlos Soares Bento, o Newton pediu, naquele tempo se pedia, que ele interferisse junto à Prefeitura, eu acho que era o tempo do Otávio Rocha, e evidente ele foi levado a Prefeitura, e deram a possibilidade de ele trabalhar lá. Em pouco tempo ele já era o diretor: criaram o serviço no qual ele foi o diretor, e evidentemente, aí vem à era Gaelzer que foi, inclusive, enquanto ele foi vivo: ele sempre foi um dos líderes (LICHT II, p. 7). 
Ao ocupar um cargo de gestão, iniciam-se as possibilidades de intervenção, consubstanciada, no caso de Gaelzer, na forma de uma política pública relacionada à urbanização articulada à Educação.

Nos processos de implementação de uma política pública, existe, por certo, uma conjuntura que possibilita sua instituição, bem como homens que a executem. No contexto deste estudo, a figura pública que se configura como responsável, em grande medida, pela criação dos Jardins de Recreio é, portanto, Francisco Guilherme Gaelzer, que, unido a uma série de circunstâncias sociais vinculadas, sobretudo, a um discurso higienista e patriótico, cria, em Porto Alegre, espaços urbanos de socialização nas suas diferentes dimensões.

Foi então, em outubro de 1926, que o “Systema de Jardins de Recreio" foi iniciado. O prefeito de Porto Alegre, Doutor Otávio Rocha, convidou o professor Frederico Guilherme Gaelzer para planejar as atividades relacionadas a esse órgão.

\footnotetext{
Porém, até 1948 não pode, este Serviço, apresentar realizações ponderáveis, como era de se esperar, em virtude de estar ele na interdependência da Diretoria de Obras, onde não encontrou a necessária compreensão de suas finalidades educacionais e, portanto, a carência de verbas. Em 9 de abril de 1948, o Sr. Prefeito Municipal, Dr. Gabriel Pedro Moacyr, dando cumprimento ao que dispõe o artigo $10^{\circ}$ do Ato das disposições Transitórias da lei Orgânica, nomeou, em Portaria $\mathrm{n}^{0} 259$, uma comissão para "estudar a localização do parque Náutico Municipal e das Praças de Educação Física, estas em todos os bairros da cidade e nos distritos" (BOLETIM TÉCNICO INFORMATIVO, 1953, p. 5).
}

Até 1942, esse sistema esteve ligado à Diretoria Geral de Obras e chamava-se "Diretoria de Praças e Jardins". A Lei 121 de (1942) criou o "Departamento Municipal de Educação Física", diretamente ligado ao Gabinete do Prefeito. E, em 1950, a Lei 500 instituiu o "Serviço de Recreação Pública", continuando a sua relação direta com o Gabinete do Prefeito. Foi somente em 27 de novembro de 1950, pelos Decretos Leis n. 500 e n. 501, que foi criado, de fato 
o Serviço de Recreação Pública (BOLETIM TÉCNICO INFORMATIVO, 1953, p. 5-6.).

É importante ressaltar que, entre 1926 e 1964, foram desenvolvidas, no Brasil, pelo menos 03 grandes experiências de recreação conduzidas pelo poder público:

(1) a recreação pública promovida pela Prefeitura Municipal de Porto Alegre, liderada por Frederico Guilherme Gaelzer (1926-1955); (2) a experiência da Divisão de Educação e Recreio do departamento de Cultura e Recreação da Prefeitura Municipal de São Paulo, liderada por Nicanor Miranda (1935-1947); e a (3) experiência do sérviço de Recreação Operária liderada, em sua primeira fase, por Arnaldo Sussekind (1943-1964) (GOMES apud PEIXOTO; PEREIRA, 2014, p. 169).

A década de 1920 foi profícua em ações que vinculavam o esporte, a recreação pública e a Educação Física à higiene. Sob uma perspectiva higienista, como convinha à época, com Gaelzer no comando, a Associação Cristã de Moços realizou, na cidade do Rio de Janeiro, o $1^{\circ}$ Congresso Brasileiro de Hygiene, em 1923, "apresentando naquele congresso tese específica sobre a educação física." (SOARES, 1994, p. 132). Em Belo Horizonte, em 1924, realizou-se o $2^{\circ}$ Congresso Brasileiro de Hygiene, unindo a Educação Física e a Higiene, tendo como objetivo a formação "eugênica da raça" (SOARES, 1994, p. 134).

Essas ações, entre outras relativas ao tema, podem ser vinculadas a duas instituições que se destacavam à época: a Associação Cristã de Moços - ACM, então coordenada por Francisco Guilherme Gaelzer, e a Associação Brasileira de Educação ${ }^{6}$ - ABE. A ABE preconizava uma educação integral7 e uma escola que ensina pela vida; em Porto Alegre, essa instituição realizou cursos de curta

\footnotetext{
${ }^{6}$ A Associação Brasileira de Educação (ABE) surgiu na década de 1920. Entre seus presidentes, estão Anísio Teixeira e Fernando de Azevedo. Diversos intelectuais da Associação Cristã de Moços (ACM) fundaram ou fizeram parte da entidade.

7 Um acontecimento marcante para a história da educação no Brasil foi a publicação do Manifesto dos Pioneiros da Educação Nova, em 1932, redigido por Fernando de Azevedo e lançado pela ABE.
} 
duração destinados à formação profissional em Educação Física.

Em 1929, a ABE estreitou laços com a ACM; nesse contexto, as Praças de Esportes e as Praças de Recreio foram temas importantes debatidos entre as duas instituições. Essas construções de espaços recreativos tiveram grande relação com o ideário da vida citadina e com a pedagogia moderna. Com isso, as praças e as escolas convergiram para um objetivo comum, constituindo-se em espaços diferenciados de educação em Porto Alegre; sobre isso Lourenço Filho (1978, p. 135) escreve:

Dentro de cada escola com mais de uma classe de alunos, igualmente se tratou de propor trabalho conjunto, em auditórios, jogos e recreação organizada, clubes e associações de alunos. Estes últimos, sob direção dos próprios alunos, discretamente orientada, tomaram a denominação de instituições escolares, no sentido de grupos sociais da própria escola, considerada como uma comunidade em miniatura, para nos servimos de uma expressão que Dewey tornou corrente.

Por isso, há necessidade de se ocupar um espaço institucional que é repleto de significados, onde há um procedimento a ser seguido e um tempo a ser "esgotado". Nessas Praças de Educação Física, "o interesse institucional em educação, esporte e recreação eram prementes" (CUNHA; MAZO; STIGGER, 2010, p. 13), tendo como objetivos a transmissão das tradições da raça e a formação de uma cidadania prestante.

É, assim, a partir do século $\mathrm{XX}$, que os porto-alegrenses começam a utilizar as praças enquanto espaços públicos de lazer. Nesse período, segundo Ghiraldelli Júnior (1989), a Educação Física regia um projeto de assepsia social, e o meio para atingir tal objetivo era educar a alma e o corpo por meio de um programa escolar-curricular rígido. "Só é perfeita a educação quando à cultura psíquica se justapuser a cultura física" (Boletim Técnico Informativo, 1953): assim era concebida a educação das praças de Porto Alegre, aliando lições morais e cívicas aos exercícios ginásticos.

Com as reflexões expostas, é possível estabelecer uma linha de conexão 
entre vida do professor Gaelzer, a implementação dos Jardins de Recreio e o Serviço de Recreação Pública de Porto Alegre.

\section{OS JARDINS DE RECREIO}

Os "Jardins de Recreio" foram uma política pública pioneira no Brasil, idealizada, como já mencionado, pelo Professor Frederico Gaelzer. Feix (2013, p. 60), ao abordar a estrutura dos jardins de recreio, afirma que "no Jardim de Recreio existia, entre outras coisas, Jardim de Infância, biblioteca, vestiários femininos e masculinos, quadras esportivas e pracinha para crianças com vários equipamentos". Um aspecto interessante distinguido pelo autor tem relação com a quantidade desses espaços: ele afirma que, "posteriormente, estes locais de recreação se multiplicaram em mais seis, que funcionam até hoje com escolinhas infantis em nossa cidade. São eles: Praça Pinheiro Machado, Praça Florida, Praça Dr. Montaury, Praça Jayme Telles, Praça Garibaldi e Praça São Geraldo” (FEIX, 2013, p. 60 -61). No mesmo documento, escreve que "os espaços de áreas verdes na cidade formaram uma rede de novas praças, grandes parques, balneários e centros comunitários, tornando a capital gaúcha como uma das cidades com mais área verdes, praças e parques do Brasil". Naquela época, diz ele, "havia o entendimento de se construir a praça perto de uma escola para que as crianças e os jovens fizessem recreação, brincassem em turno alternativo, aprendessem esportes, praticassem a leitura e se relacionassem" (FEIX, 2013, p. 60-61, grifo nosso).

Todos os Jardins eram construídos próximos às escolas; nesses locais, em período integral, ficavam as crianças com até 6 anos e, em meio período, as crianças maiores, que frequentavam as escolas. Dentro das atividades contempladas nas praças e parques, estavam as exposições, os concertos, as excursões orientadas, os campeonatos, as comemorações cívicas e folclóricas.

A política pública conhecida como Jardins de Recreio tratava-se, 
portanto, de um modo de pensar a infância desde a mais tenra idade, visando a fomentar hábitos saudáveis e eliminar atitudes insalubres; resguardar as crianças da debilidade e das moléstias; construir e gerar um sistema de ação colaborativa, capaz de conduzir os infantes para uma vida de prevenção e preservação. Esses eram os objetivos que faziam parte da incumbência do Estado em relação às suas intervenções no começo do século XX. Tais objetivos fomentaram a criação e a permanência do Serviço de Recreação Pública da cidade de Porto Alegre, fator perceptível no Boletim Técnico Informativo, o qual destaca:

Também no setor educacional notamos, entre outros, a transformação das atividades da infância que aos poucos foram perdendo o valor formativo dos atributos que nela promoviam seu enriquecimento, sua vitalidade e fôrça. Ao reconhecermos que todo o desenvolvimento tem a sua origem em alguma atividade, devemos nos esforçar em manter, conduzindo-as, agora já sob nova forma, as sãs ocupações da infância das épocas passadas: uma vez que a saúde, a cidadania, a moralidade e mesmo a intelectualidade não são qualidades abstratas, que diretamente podem ser asseguradas, elas têm e são o caráter resultante da ação. [...] É com esta finalidade que devemos criar e manter a recreação pública, que é um verdadeiro complemento da escola (BOLETIM TÉCNICO INFORMATIVO, 1953, p. 01).

Em outra passagem, assegura que "nas conclusões de um Congresso Educacional afirmaram ser mais vantajoso a uma comunidade, a existência de um jardim de recreio bem organizado sem uma escola, do que uma escola formal, sem um jardim de recreio" (BOLETIM TÉCNICO INFORMATIVO, 1953, p. o1). Tal afirmação visibiliza a importância atribuída aos Jardins de Recreio.

Deste modo, em 1926, é inaugurado o primeiro Jardim de Recreio na Praça Alto da Bronze (Fig. 1), no governo do Intendente Otávio Rocha ${ }^{8}$. Feix e Goellner (2008) relatam que os Jardins de Recreio se multiplicaram pela cidade com o objetivo de modificar a imagem de cidade rural. Segundo Stigger, Trentini e Freitas (2009, p. 47), “já desde 1926, com a criação do primeiro Jardim de

\footnotetext{
${ }^{8}$ Essa praça, hoje, recebe o nome de General Osório.
} 
Recreio de Porto Alegre, identifica-se, na cidade uma iniciativa governamental que visa a oferecer serviços no âmbito do lazer para os cidadãos”.

O espaço em questão possuía salas de aula destinadas ao Jardim de Infância, área externa com brinquedos de balanço, escorregador, gangorra, tanque de patinhar, canchas de bola ao cesto, voleibol, basebol e biblioteca.

Figura 1 - Praça Alto da Bronze, 1929.

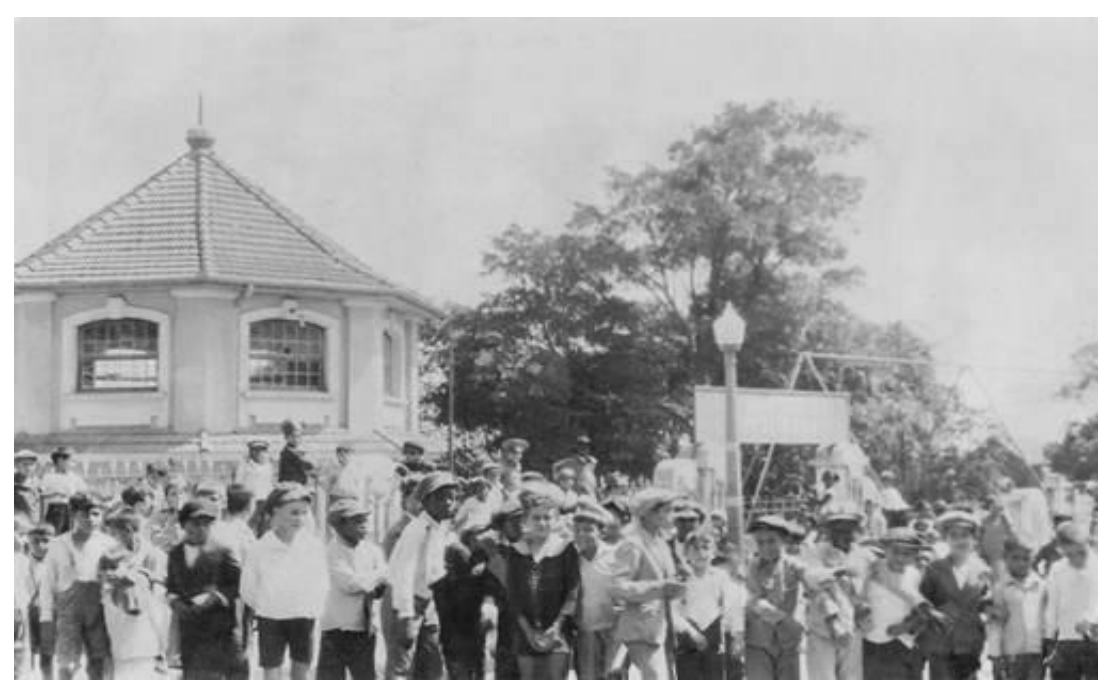

Fonte: Centro de Memória do Esporte, UFRGS. ${ }^{9}$

Conforme o Boletim Técnico número 07 (1953), criaram-se os Jardins de Recreio dentro das praças públicas, pois tão importante quanto às aulas nas escolas era o fato de que "[...] o aluno deve empregar cinquenta por cento de seu tempo disponível em plena natureza”. Essas estruturas eram consideradas complementos das escolas; foram, portanto, construídas perto de instituições escolares. Nessas praças, havia aparelhos de ginástica, canchas, gramados para esportes, além de pavilhões para área administrativa e social.

As atividades eram organizadas por faixa etária. No matutino, eram atendidas as crianças em idade pré-escolar; no vespertino, ao terminarem as

\footnotetext{
9 Disponível em: http://www.lume.ufrgs.br/bitstream/handle/10183/9944/Rg1000000160.jpg? sequence $=1$.
} 
aulas, os jovens tinham um instrutor que organizava programas específicos de jogos. Já no turno da noite, todas as tarefas eram voltadas para a classe laboriosa:

Durante a manhã dispensa-se especial cuidado em organizar actividades para os menores, de idade pré-escolar. Para isto conta cada jardim com um recanto infantil, com seu tanque de patinar, circundado pelo comoro de areia. É aí que os pequeninos satisfazem os seus primeiros instinctos criadores, encontrando mais, à sua disposição, balanços, gangorras, delisadores, trapézios, argollas. A tarde, ao terminarem as aulas dos collegios, com a affluencia dos escolares, mui naturalmente muda a feição do trabalho. É então que o instructor organiza programmas com jogos que venham a unir os rapazes nesta idade individualista, congraçando-os em sociedade, clubs e quadros; incutindo-lhes a sociabilidade e a união do esforço, agentes tão necessários para a vida futura. Para isto contam os jardins lindos gramados, canchas de baseball, volley-ball, bochas e malha. E é só lá pelas seis horas que o jardim toma nova feição. $\mathrm{O}$ encerramento das fábricas e casas commerciais e a terminação das actividades do dia trazem à praça de desportos publica a mocidade laboriosa, que aproveitando as últimas horas úteis do dia, procura reganhar physicamente o que foi estancado durante horas sedentárias dos seus empregos. E é a esta hora que a direcção da praça volta a sua actenção para este elemento que por certo é o mais merecedor, por ser o mais necessitado (BOLETIM TÉCNICO INFORMATIVO, 1953, p. 4).

Os Jardins de Recreio apresentavam, como justificativa, a melhoria do aproveitamento das horas de lazer, educando as crianças por meio de lições morais e cívicas, fato esse expresso no seguinte excerto:

O maior compromisso da criança não é o de passar por exames, porém o de crescer sadiamente. E para isto ela tem necessidade de brincar; uma exigência vital que está inserida no próprio organismo. Sua utilidade é de tal evidência, seus efeitos sôbre a vida física e psíquica de tal ordem, que se fica surprêso vendo a indiferença ou quase desprêzo com que foi sempre tratada (BOLETIM TÉCNICO INFORMATIVO, 1953, p. 1).

Havia um elo entre a parte educacional e o Serviço de Recreação Pública, demonstrado pela entrevista ao Diário de Notícias, em 31 de março de 1929, em 
que Frederico Gaelzer afirma: "Quando um país quer revelar a medida do seu progresso, do alcance de suas instituições, do valor da sua raça, aponta o número de suas coisas de educação e abre-lhes as suas portas como que dizendo: Vede como se educa!” (p. 31). Frederico também narrava os Jardins como sendo um lugar de formação para a cidadania de uma nova sociedade, proporcionando às crianças um lugar seguro,

Impedindo-as do perambular ocioso pelas ruas e colocando-as em contacto diário com outras crianças dentro de um ambiente apropriado a essa idade, estão os parques infantis, contribuindo enormemente para a formação do cidadão ideal do mundo que há de vir (BOLETIM TÉCNICO INFORMATIVO, 1953, p. 8).

Logo, esse sujeito precisa estar na escola em um turno e, no turno seguinte,

[...] nos jardins e parques recreativos, complementos das escolas, com todos os seus matizes educadores, que a criança desenvolverá o corpo e a mente, ampliando a sua vida social em um convívio conduzido entre os seus companheiros e folguedos (BOLETIM TÉCNICO INFORMATIVO, 1953, p. 1).

Pode-se afirmar que as praças representam um fenômeno sociocultural e político relevante por três motivos: a adesão da população à frequência nas praças; o associativismo ou seja, a criação dos clubs; e a institucionalização do Serviço de Recreação Pública. Segundo relatórios, a frequência mensal de pessoas às praças passava de vinte e cinco mil jovens e crianças, sendo que a população da capital não chegava a duzentos mil habitantes. Em relação ao associativismo, havia clubs organizados nas praças entre as décadas de 1920 a 1940. Segundo Cunha e Mazo (2010), após a instauração desses clubs, uma diretoria era escolhida para organizar o funcionamento das praças.

É possível notar, então, o discurso sobre a importância da recreação 
integrada a atividades de aprendizagem, como um contraponto à ideia de passatempo ou ocupação de horas vazias. Esse sentido é evidenciado em um excerto de uma conferência pronunciada por Frederico Gaelzer, no salão nobre da Faculdade Católica de Filosofia. Segundo o professor,

\begin{abstract}
Com o afluxo, cada vez maior, do homem do campo para a cidade, inúmeros são os novos problemas que se apresentam à sociedade. Também no setor educacional notamos, entre outros, a transformação das atividades da infância que aos poucos foram perdendo o valor formativo dos atributos que nela promoviam seu enrigecimento, sua vitalidade e fôrça. Ao reconhecermos que todo o desenvolvimento tem a sua origem e alguma atividade, devemos nos esforçar em manter, conduzindo-as, agora já sob nova forma as sãs ocupações da infância das épocas passadas; uma vez que a saúde, a cidadania, a moralidade e mesmo a intelectualidade não são qualidades abstratas, que diretamente podem ser asseguradas, elas têm e são o caráter resultante da ação. Eis a razão de procuramos manter, nos aglomerados humanos das cidades, atividades semelhantes as de nossos antepassados, em longínquos rincões. É com esta finalidade que devemos criar e manter a recreação pública, que é um verdadeiro complemento da escola (1950, p. 1, grifo nosso).
\end{abstract}

Observa-se, nesse trecho, o objetivo de se fomentar a recreação pública na cidade de Porto Alegre. Portanto, os Jardins de Recreio, ao oferecer às crianças atividades como os jogos, o teatro, a dança, a música e as aulas na biblioteca, apresentavam uma intenção pedagógica, visando ao estabelecimento de uma nova sociedade moderna urbano-industrial. Segundo Marcellino (1996, p. 50), “o lazer é um veículo privilegiado da educação [...]”; logo, nessa perspectiva, transforma-se em um meio interessante e necessário. Portanto, os Jardins de Recreio foram uma política pública que difundiu conteúdos educacionais importantes para seu tempo.

Em outro excerto sobre o Decálogo da Recreação Popular, é relatado o seguinte: 
Hoje em dia o Estado assegura a organização e os meios para a recreação popular - entendendo por recreação toda a atividade que o homem realiza em suas horas livres. Ela é um meio autêntico para o aperfeiçoamento do cidadão, e portanto, de vital importância para o progresso social da comunidade. A Recreação completa a formação física; complementa a educação e favorece o aperfeiçoamento da aptidão profissional; cultiva o caráter e a personalidade mediante um programa integral de atividades físicas e culturais (BOLETIM TÉCNICO INFORMATIVO, 1953, p. 12).

Quanto ao Serviço de Recreação Pública, já mencionado anteriormente, é importante sinalizar e reforçar sua vinculação aos Jardins de Recreio. Em uma articulação entre os dois, o Serviço tinha por finalidade desenvolver as atividades comunitárias, fazendo com que crianças, adolescentes e adultos tivessem um aproveitamento útil e sadio do tempo disponível para uma recreação organizada, orientada e instrutiva. Competia a esse órgão executivo:

a) Estudar a planificação da cidade no que concerne ao bom aproveitamento das novas construções, loteamentos, arruamentos e praias, sugerindo o que for de vantagem para a recreação pública e criando novos Jardins de Recreio, Praças de Educação Física, Praias e Parques Recreativos Suburbanos;

b) Interpor os seus bons ofícios na organização das verbas anuais do Município, propondo novas verbas quanto à ampliação das atividades do SRP;

c) Promover intensa cooperação com a Secretaria de Educação e Cultura na utilização dos próprios Estaduais no fomento da recreação pública e auxiliar a elaboração dos planos das construções para os novos prédios escolares, advindo do convênio entre o Estado e o Município;

d) Aconselhar as organizações desportivas e sociais em suas atividades relacionadas com a recreação de seus sócios;

e) Fornecer os elementos necessários para que a Diretoria Geral da Receita possa arrecadar os tributos originados pelos seus serviços;

f) Intervir na recreação comercial, quando assim for aconselhável em benefício da recreação pública;

g) Promover festividades públicas com o auxílio da banda Municipal e do Teatro Amador também nos bairros populosos da Capital;

h) Promover cursos, conferências e convocar congressos no afim de 
incrementar favoravelmente a opinião pública sobre a recreação organizada.

Sendo assim, foi em um espaço instituído nas praças, denominado Jardins de Recreio, que se planejou e moldou cada área e lugar da cidade, pensando-se na recreação. Segundo o Boletim Técnico Informativo n. 5, de 1953, a construção das Praças de Recreação nem sempre era em uma área ideal. Logo,

[...] sempre constatamos variantes nos tamanhos e acidentes dos terrenos. Devemos, entretanto, formar doutrina quanto à utilização eficiente de suas instalações. Com este fim convém estabelecer-se uma classificação de acôrdo com a sua importância e possibilidade em servir a comuna que a cerca (p. 1).

Na mesma Lei n. 500, de 27 de novembro de 1950, que cria o Serviço de Recreação Pública, sob o Art. 11, consta que foram ainda criados os seguintes serviços: Serviço de Praças, Serviço de Praias, Serviço de Extensão, Serviço de Expansão Cultural e Artística e Serviço de Material.

Conforme o documento, a Secção de Praças e Parques de Recreação foi gerenciada de acordo com os tipos de praças e parques existentes na cidade:

[...] é uma das muitas secções integrantes da Prefeitura Municipal e que está subordinada, diretamente, ao Prefeito. Sua finalidade principal é estimular, coordenar, orientar e dirigir as atividades recreativas do povo, adequadas às horas de lazer [...] O S. R. P. oferece ambiente a uma sã recreação, não só das crianças como dos adultos. Há os recantos infantis construídos dentro de uma Praça Pública qualquer. Nesses recantos há gangorras, balanços para bebê, escorregadores, caixa de areia, etc. Por exemplo: recantos da Praça da Alfândega, da Conceição, Otávio Rocha, etc. Há os Jardins de Recreio, que são construídos junto a algum estabelecimento de ensino. Possuem os mesmos aparelhos que o recanto. Exemplo: Jardim de Recreio, ao lado do Instituto de Educação (BOLETIM TÉCNICO INFORMATIVO, 1953, p. 6).

Analisando-se a repercussão dessa política pública na mídia, mais 
especificamente em jornais da época, não foi encontrada nenhuma publicação com conotação negativa a respeito dos Jardins de Recreio. Ao contrário, a política pública estava sempre recebendo elogios pelo papel que desempenhava, tanto nos jornais locais - "A Federação", "Correio do Povo", "Diário de Notícias" -, quanto em jornais de outros estados, como "O Jornal”, do Rio de Janeiro.

Além disso, logo após a inauguração do Jardim de Recreio número um, na Praça Alto da Bronze, nota-se, por meio dos Boletins Técnicos Informativos, depoimentos e Relatórios, que tais espaços se diferem dos atendimentos realizados nas escolas; com isso, eram propagandeados na imprensa local. São referidos, por meio do jornal "A Federação", como a "pérola da educação" da cidade, a qual deveria ser disseminada. Foi nos Jardins de Recreio que as ações pedagógicas se vincularam a uma concepção de fortalecimento físico, mental e moral dos seus usuários, com a intencionalidade de tornar a cidade de Porto Alegre um lugar limpo, organizado, belo e saudável.

Dessa forma, em uma conjuntura social e política estabelecida nas primeiras décadas do século $\mathrm{XX}$, que consubstancia um conjunto de ações públicas, os Jardins de recreio aparecem relacionados a um contexto de desenvolvimento da moral e da cidadania, pautados nos princípios higienistas.

\section{CONSIDERAÇÕES FINAIS}

Neste estudo, investigou-se a criação e o funcionamento dos Jardins de Recreio, durante o período 1926 e 1950, em que foi mais intensa sua atuação. Nesse processo, percebe-se que a criação desses espaços está conectada a um contexto social mais amplo; seu funcionamento respondia a diferentes demandas fundamentadas a determinadas condições históricas - condição essa relacionada, entre outros aspectos, ao discurso médico-higienista que reverberava em distintas instâncias e espaços.

Em virtude dos indícios que indicam sua criação como política pública 
pensada e gerada a partir de diversos discursos que circulavam à época, não se acredita que os Jardins de Recreio, bem como o Serviço de Recreação Pública, pudessem ter sido concebidos pelo acaso de uma ideia surgida de uma única pessoa - no caso, o professor Frederico Guilherme Gaelzer. Integraram, sim, um conjunto de iniciativas implementadas pelo Serviço de Recreação Pública que visavam à ocupação do espaço urbano coletivo, articulada às intervenções pedagógicas.

Dessa forma, pode-se afirmar que o contexto em que política pública Jardins de recreio ocorreu está vinculado às modificações relacionadas às novas ideias de urbanização, acompanhadas de um ideário higienista e de exacerbação do nacionalismo que despontam, sobretudo, entre os anos 1920 e 1930. São características que estão sob a influência do escolanovismo e do ideário republicano, como parte integrante de um projeto de reforma social da cidade.

O professor Gaelzer, idealizador e executor de tal proposta, tinha a preocupação de oferecer não apenas aparelhos para práticas de esporte e lazer, mas desenvolver tarefas pedagógicas. Salienta-se a existência de uma diversidade de aparelhos dispostos nas praças de livre acesso a população. Assim, pode-se concluir que uns dos objetivos do professor Gaelzer era aumentar a frequência das pessoas nos espaços públicos de lazer, que se ampliavam a cada dia naquele princípio de século XX.

É possível pontuar que o estudo aqui apresentado possibilizou a identificação e a sistematização das informações relativas à organização de uma rede de ações relacionadas à administração pública, cujo objetivo era, entre outros, o desenvolvimento de um ideal de nação. De forma sintética, retomou-se a construção histórica dessa rede, vinculando-a à institucionalização do Serviço de Recreação Pública.

Acredita-se ser importante pensar essa produção como ponto de partida para mais uma jornada, na qual serão traçados outros trajetos e percursos. Muito há ainda a perguntar sobre a história da educação em espaços não formais e a sua relação com a urbanidade, em determinados períodos históricos. À guisa de 
conclusão, segue uma reflexão importante que liga essa construção histórica ao presente: todo esse aparato que serviu a um sistema de urbanização e de urbanidade, e que implicou diretamente a melhora das condições de recreação dos porto-alegrenses por 90 anos, foi extinto pela administração pública que assumiu em 2017.

\section{REFERÊNCIAS}

CASTELLS, Manuel. A sociedade em rede. São Paulo: Paz e Terra, 2010.

CHALHOUB, Sidney. Cidade fabril: cortiços e epidemias na corte imperial. São Paulo: Companhia das Letras, 1996.

CUNHA, Maria Luisa Oliveira da; MAZO, Janice Zarpellon. A criação dos clubs nas praças públicas da cidade de Porto Alegre (1920-1940). Revista

Brasileira de Ciência e Esporte, Florianópolis, v. 32, n. 2-4, p. 123-139, 2010.

CUNHA, Maria Luisa Oliveira da; MAZO, Janice Zarpellon; STIGGER, Marco Paulo. A organização das praças de Desporto/Educação Física na cidade de Porto Alegre (1920-1940). Revista Licere, Belo Horizonte, v. 13, n. 1, p. 1-33, 2010.

ELIAS, Norbert. O processo civilizador II: formação do estado e civilização. Rio de Janeiro: Jorge Zahar, 1993.

FARGE, Arlette. O sabor do arquivo. São Paulo: Editora da Universidade de São Paulo, 2009.

FEIX, Eneida. A dimensão lúdica do esporte: as praças e parques, os jardins de recreio e colônia de férias. In: GOELLNER, Silvana Vilodre; MÜHLEN, Johanna Coelho Von (org.). Memórias do esporte e do lazer no Rio Grande do Sul. Porto Alegre: Fundergs, 2013. p. 53-64.

FEIX, Eneida; GOELLNER, Silvana Vilodre. O florescimento dos espaços públicos de lazer e de recreação em Porto Alegre e o protagonismo de Frederico Guilherme Gaelzer. Revista Licere, Belo Horizonte, v. 11, n. 3, 2008.

GHIRALDELli JÚNIOR, Paulo. Educação Física Progressista: a pedagogia crítico-social dos conteúdos e a Educação Física brasileira. São Paulo: Loyola, 
1989.

GOELLNER, Silvana Vilodre; MACEDO, Christiane Garcia; SILVA, Carina Kaiser da. Repositório Digital do Centro de Memória do Esporte: notas sobre a coleção Lazer e Recreação. Revista Licere, Belo Horizonte, v. 16, n. 1, 2013. HALBWACHS, Maurice. A memória coletiva. São Paulo: Vértice, 1990. HUNT, Lynn. A nova história cultural. São Paulo: Martins Fontes, 1992. LOURENÇO FILHO, Manuel Bergström. Introdução ao estudo da Escola Nova. 13 ed. São Paulo: Melhoramentos, 1978.

MARCELLINO, Nelson Carvalho. Estudos do lazer. Campinas: Autores Associados, 1996.

PECHMAN, Robert Moses. O urbano fora de lugar? Transferências e traduções das ideias urbanísticas nos anos 20. In: RIBEIRO, Luiz Cesar de Queiroz; PECHMAN, Robert (org.). Cidade, povo e nação: gênese do urbanismo moderno. Rio de Janeiro: Civilização Brasileira, 1996. p.331-362.

PEIXOTO, Elza Margarida de Mendonça; PEREIRA, Maria de Fátima Rodrigues. Políticas de educação não formal - a recreação (1889-1961). Revista HISTEDBR, Campinas, n. 55, p. 168-179, 2014.

PESAVENTO, Sandra Jatahi. O imaginário da cidade: visões literárias do urbano - Paris, Rio de Janeiro, Porto Alegre. Porto Alegre: UFRGS, 1999.

POPKEWITZ, Thomas. Ciências da educação, escolarização e abjeção: diferença e construção da desigualdade. Rev. Edu. Real., Porto Alegre, v. 35, n. 3, set./dez. 2010.

SOARES, Carmem Lúcia. Educação Física: raízes europeias e Brasil. Campinas: Autores Associados, 1994.

STEPHANOU, Maria. Bem viver em regras: urbanidade e civilidade em manuais de saúde. Rev. Educação Unisinos, v. 10, n. 1, 2006.

STEPHANOU, Maria. Práticas formativas da medicina: manuais de saúde e a formação para a urbanidade. Véritas, Porto Alegre, v. 43, n. especial, p. 97-102, dez. 1998.

STIGGER, Marco Paulo; TRENTINI, Edson Bertuol; FREITAS, Maitê Venuto de. Parques públicos, sociabilidades urbanas e políticas de lazer. In: FRAGA, Alex Branco; MAZO, Janice Zarpellon; STIGGER, Marco Paulo; GOELLNER, Silvana Vilodre (org.). Políticas de lazer e saúde em espaços urbanos. 
Porto Alegre: Gênese Editora, 2009.

TOPALOV, Christian. Da questão social aos problemas urbanos: os reformadores e a população das metrópoles em princípios do século XX. In: RIBEIRO, Luiz Cesar de Queiroz; PECHMAN, Robert (org.). Cidade, povo e nação: gênese do urbanismo moderno. Rio de Janeiro: Civilização Brasileira, 1996. p. 23-52.

FABIANA GAZZOTTI MAYBORODA é doutoranda do Programa de PósGraduação em Ciências do Movimento Humano da Escola de Educação Física, Fisioterapia e Dança (Esefid) da Universidade Federal do Rio Grande do Sul (UFRGS). Mestre em Educação pela Universidade do Vale do Rio dos Sinos (Unisinos, 2017), na linha de pesquisa: História, Políticas Públicas e Educação. Possui graduação em Pedagogia - habilitação em Supervisão e Administração Escolar, com ênfase em Psicopedagogia, pela Universidade Feevale (2005). Especialista em Educação Integral e Integrada na Escola Contemporânea pela Faculdade de Educação (Faced)/Universidade Federal do Rio Grande do Sul (UFRGS, 2013). Pertence à Associação Nacional de Pós-Graduação e Pesquisa em Educação (Anped). Membro associado do Colégio Brasileiro de Ciências do Esporte (CBCE). Participa do Grupo de Estudos Socioculturais em Educação Física (Gesef/UFRGS), do Grupo de pesquisa Educação no Brasil: memória, instituições e cultura escolar (Ebramic/Unisinos) e do Grupo de Estudos em Práticas Corporais (Gepraco/Uergs). Atuou na área da Educação como: assessora pedagógica da Secretaria de Educação, professora da Sala de Recursos Multifuncional e coordenadora pedagógica da Educação Infantil, dos Anos Iniciais e dos Anos Finais pela Prefeitura Municipal de Novo Hamburgo, Rio Grande do Sul.

E-mail: f.mayboroda@gmail.com

(iD) http://orcid.org/0000-0001-8830-5762

LUCIANE SGARBI SANTOS GRAZZIOTIN é doutora em Educação, ênfase em História da Educação pela Pontifícia Universidade Católica/RS (PUCRS) (2008). Fez doutorado-sanduíche na Universidade Clássica de Lisboa (2007) e pós-doutorado na Universidad Nacional de Educación a Distancia (Uned) em Madri (bolsa Capes, 2017). Fez Mestrado em Ciências (1991) e graduação em Biologia - Licenciatura. É membro da Sociedade Brasileira de História da Educação (SBHE) e da Associação Sul-Rio-Grandense de Pesquisadores em História da Educação (Asphe), vice-presidente dessa associação (gestão 2011-2013). Pertence à Associação Nacional de Pós- 
Graduação e Pesquisa em Educação (Anped). Líder do Grupo de pesquisa Educação no Brasil: memória, instituições e cultura escolar (Ebramic/Unisinos) (CNPq) e participa do Grupo de pesquisa Memórias e Histórias da escola do Rio Grande do Sul: do Deutscher Hilfsverein ao Colégio Farroupilha (1858-2008) (CNPq). Atualmente é professora e pesquisadora na graduação e no Programa de Pós-Graduação em Educação da Escola de Humanidades da Universidade do Vale do Rio dos Sinos (Unisinos).

E-mail: lusgarbi@terra.com.br

(b) http://orcid.org/0000-0001-5648-3855

Recebido em: 07 de outubro de 2017

Aprovado em: 21 de maio de 2018 